\title{
Intraoperative Assessment of Ultrasound Guided Continuous Facia Iliaca Block (CFIB) Versus Continuous Lumbar Plexus Block (CLPB) in Patients Undergoing Fracture Neck Femur Fixation
}

\author{
MOHAMMED A. HASSAN, M.D.; HALA E. MOHAMMED, M.D.; AMR Z. MANSOUR, M.D. and \\ MOHAMMED A. MANSOUR, M.D. \\ The Department of Anaesthesiology, Surgical ICU \& Pain Management, Faculty of Medicine, Cairo University
}

\begin{abstract}
Background: In the elderly and high risk patients, it is logic to prefer local anaesthesia rather than general anaesthesia. The fascia iliaca compartment block is an easy, available method for peri-operative analgesia in patients with painful conditions affecting the thigh, the hip joint and/or the femur. Lumbar plexus block is another form of deep blocks which is used to provide anesthesia and/or analgesia for the entire distribution of the lumbar plexus.
\end{abstract} CLPB

Aim of Study: Intraoperative assessment of CFIB versus

Material and Methods: 40 patients with fracture neck femur were randomized intone of 2 blocks, CFIB and CLPB.

Results: CFIB was significantly superior to CLPB as regards shorter time for catheter insertion (CIT) $(p<0.001)$, earlier maximum motor block $(p<0.001)$ and earlier peak of sensory block $(p=0.008)$, intraoperative hemodynamic stability $(p<0.001)$ while CLPB group showed significantly rapid onset of motor and sensory block $(p<0.001, p<0.001)$.

Conclusion: Continuous infusion fascia iliaca block gives better quality analgesia. It is an easy procedure that could be done in the emergency room. It is faster, safer and more applicable technique than continuous lumbar plexus block.

Key Words: Continuous facia iliaca block-Continuous lumbar plexus block-Intraoperative assessment.

\section{Introduction}

IN the elderly and high risk patients, it is logic to prefer local anaesthesia rather than general anaesthesia [1]

The fascia iliaca compartment block is an easy, available method for peri-operative analgesia in patients with painful conditions affecting the thigh, the hip joint and/or the femur [2] .

Correspondence to: Dr. Mohammed A. Hassan, E-Mail: Dr mohammedalihassan82@yahoo.com
Lumbar plexus block is another form of deep blocks which is approached posteriorly. It is used to provide anesthesia and/or analgesia for the entire distribution of the lumbar plexus. The needle used in this block is deeply placed so, the potential systemic toxicity is greater than it is with superficial blocks [3].

As suggested by meta-analysis of previous studies, the use of US guidance to provide nerve block is more successful, faster to provide, has longer block time and carries less risk for complications [4].

\section{Patients and Methods}

This prospective randomized controlled trail was carried out at department of Anesthesiology, Intensive Care and Pain Management, Kasr ElAiny Hospital from July 2014 to July 2015, after permission from the Hospitals Ethics committee and written informed patients consent.

Forty patients, belonging to American Society of Anesthesiologists physical status (ASA) I to III, between age 40 to 70 years old scheduled for fracture neck femur fixation were selected and divided into two equal groups 20 patients each (Group continuous fascia iliaca block (CFIB) and Group continuous lumbar plexus block (CLPB)). Informed written consent was taken from the patients selected for the study. Each patient was visited in the ward, the evening before surgery for detailed pre- anesthesia assessment.

\section{Inclusion criteria:}

- Patients American Society of Anesthesiologists status (ASA) I to III. 
- Age group: 40 to 70 years; scheduled for neck femur fracture fixation surgery.

- BMI: $20-30 \mathrm{~kg} / \mathrm{m}^{2}$.

- Gender: Both sexes.

- Patient accepted technique of treatment.

- Expected operative time 2-4 hours.

\section{Exclusion criteria:}

- ASA physical status score of more than III

- Patient with BMI of more than $30 \mathrm{~kg} / \mathrm{m}^{2}$.

- Patients refusing the procedure or uncooperative or needed GA.

- Local sepsis or infection at puncture site.

- Allergy to any of the drugs used in the study.

- Diabetic peripheral neuropathy or have a history of stroke with lesion affecting the side to surgery were excluded from the study.

- INR $>1.5$ or $<12$ hours post LMWH (many practitioners consider a posterior approach to lumbar plexus comparable to central neuroaxial blockade) (Patton and Warman, 2012).

Methodology in details:

Preoperative assessment:

Routine preoperative assessment was done for every patient including:

A- History:

For general or local anesthesia and any accompanied complications, medical problem and history of drug intake.

\section{$B$ - Examination:}

General examination:

- Vital data (pulse, blood pressure and respiratory rate).

- Clinical examination of the chest and heart.

- Examination for jaundice, cyanosis, anemia, clubbing and edema.

Local examination:

- Airway examination.

- Examination to the site of injection.

C- Investigations:

- Complete blood count.

- Coagulation profile (prothrombin time and concentration).

- Liver and kidney function test.

- Random blood sugar.

- ECG.

\section{1- Preoperative preparation:}

A- Preparation of the patient:

- Patient consent was taken for spinal and regional anesthesia.

- Maintain the therapeutic drugs (that are not contraindicated with regional anesthesia) till morning of operation.

- Patient informed before the operation about visual analogue scales.

- Peripheral 18 gauge intravenous cannula was inserted and $10 \mathrm{ml} / \mathrm{kg} / \mathrm{hr}$ ringer solution was given as preload.

\section{B-Preparation of the equipment and drugs:}

- A standard general anesthesia tray is prepared.

- Standard regional anesthesia tray is prepared with the following equipment:

o Sterile towels and $4 * 4$ gauze packs.

o 25 G Quincke spinal needle.

o Hyperbaric bupivacaine $0.5 \%$.

o Isobaric bupivacaine hydrochloride $0.5 \%$

o Syringes with local anesthetic lidocaine

o Sterile gloves, marking pen and surface electrode.

o Fentanyle and midazolam ampule.

o Peripheral nerve stimulator.

o Ultrasound machine with a low-frequency $(2-5 \mathrm{MHz})$ curved array probe and a highfrequency $(7-12 \mathrm{MHz})$ linear probe.

o Catheter kit Contiplex ${ }^{\circledR}$ :

- Including a $10 \mathrm{~cm}$ stimulating needle 18 guage and a catheter 20 guage for CLPB.

- Including a $4 \mathrm{~cm}$ stimulating needle 18 guage and a catheter 20 guage for CFIB.

o Accufuser@ Varicon silicone balloon infuser control pump.

\section{2-Intraoperative management:}

- Standard monitoring was applied (ECG, NIBP, sPO2) were connected to the patient. Baseline hemodynamic readings were recorded before starting the technique, at the beginning of procedure and every 5 minutes.

- Sedation was achieved with IV midazolam $(0.03 \mathrm{mg} / \mathrm{kg})$ and Fentanyl $(50-75 \mu \mathrm{g})$.

- Then the patients were assigned to one of two groups according to the block form:
1- Group-1 (CFIB), no=20
2- Group-2 (CLPB), no=20 
Patients were divided into two equal groups and were subjected to one of the regional blocks first then spinal anesthesia.

\section{Group-1 (CFIB):}

The patient was placed in supine position. The landmarks for this block are the anterior superior iliac spine (ASIS) and the pubic tubercle of the same side. One middle finger was placed on the ASIS and the other middle finger on the pubic tubercle. A line was drawn between these two points. This line was divided into thirds (the index finger of both hands can be used). The point was marked $1 \mathrm{~cm}$ caudal from the junction of the lateral and middle third. This is the injection entry point. With ultrasound (US) the aim is to visually identify the femoral nerve and fascia iliaca and place the local anaesthetic beneath the fascia, lateral to the femoral nerve.

A high frequency ultrasound probe $(13-16 \mathrm{MHz}$, linear array) was used in a transverse direction over the anterior thigh below the inguinal ligament. The needle was advanced until the tip is placed underneath the fascia iliaca and the catheter was introduced.

\section{Group-2 (CLPB):}

The patient was placed in the lateral decubitus position with the side to be operated upper most, and the area was prepared and draped in a sterile fashion. The ultrasound scan was performed using a low frequency, 2-5 MHz, curved array transducer. Liberal amounts of ultrasound gel were applied to the skin over the lumbar paravertebral region for acoustic coupling and the ultrasound transducer was positioned approximately $3-4 \mathrm{~cm}$ lateral and parallel to the lumbar spine, with its orientation marker directed cranially, so as to produce a longitudinal scan of the lumbar paravertebral region.

First, the kidney was visualized; the transducer was then moved caudally, while still maintaining the same orientation, until the sacrum and the L5 transverse process were visible. The lumbar transverse processes were identified by their hyperechoic reflection and an acoustic shadow distal (anterior) to them, which is typical of bone. Once the L5 transverse process was located, the other lumbar transverse processes were identified by counting them from below upwards. The transducer was finally positioned over the L2, L3, and L4 transverse processes. Identification of the kidney, peritoneum, and intestine was done first. With the lumbar ultrasound "trident" in view, the lumbar plexus was identified by being hyperechoic structure.
After local anesthetic skin infiltration "lignocaine" $2 \%, 2-3 \mathrm{ml}$, a $10 \mathrm{~cm}, 20$ gauge insulated needle connected to a Peripheral nerve stimulator with initial current intensity of $1.0 \mathrm{~mA}(2 \mathrm{~Hz}, 0.1$ millisecond) was introduced in-plane with the probe. The lumbar plexus was finally identified by eliciting quadriceps contraction at current below $0.4 \mathrm{~mA}$. The catheter was then inserted in the needle and advanced $3 \mathrm{~cm}$ beyond the needle tip. The needle was then with drawn and the catheter was tunneled and fixed with a sterile medication.

After negative aspiration, activation of the blocks was performed by injecting $30 \mathrm{ml}$ and $40 \mathrm{ml}$ of $0.125 \%$ bupivacaine in CFIB and CLPB respectively. Injection was done incrementally over 5 minutes. Vital signs monitoring was continued for 30 minutes after bolus dose.

Sensory blockade was assessed in the cutaneous distribution of the femoral nerve (anterior aspect of the thigh), the lateral femoral cutaneous nerve (lateral aspect of the thigh) and the obturator nerve (medial aspect of the thigh) by using cold perception or pinprick. Assessment was done using the 3 point scale for sensory assessment: $0=$ Complete loss, $1=$ Partial loss, $2=$ Normal sensation.

Motor blockade was assessed by femoral and obturator nerve function (knee extension and thigh adduction). Movement was classified according to modified Bromage scale: No weakness $=0$, partial weakness $=1$, almost complete weakness $=2$, complete weakness $=3$.

All assessements were undertaken approximately every two minutes for 30 minutes. The block was considered unsuccessful if the patient failed to develop decreased sensation over the ipsilateral distal thigh and weakness upon knee extension relative to the contralateral limb within 30 minutes.

After securing the catheter in both groups with tap and benzoin the spinal anesthesia was performed with $3 \mathrm{ml}$ of hyperbaric bupivacaine $0.5 \%(15 \mathrm{mg})$ at L4-L5 interspace with a 25G Quincke spinal needle after local infiltration of $3 \mathrm{ml}$ of $2 \%$ xylocaine.

At the end of the surgery and after termination of the effect of spinal anaesthesia (3-4 hours), a continuous infusion pump was connected to the catheter. Infusion regimen was started by the use of local anesthetic (plain bupivacaine $0.125 \%+$ fentanyle $2 \mathrm{ug} / \mathrm{ml}$ ) at a rate of $6-10 \mathrm{ml} / \mathrm{hr}$ for $48 \mathrm{hrs}$. The catheter was removed after $48 \mathrm{~h}$.

The following was assessed:

1- Catheter insertion time. 
2- Assessment of the block in the form of:

- Sympathetic block by ipsilateral warming.

- Sensory block by pinbrick. Assessment of time of onset, time to reach maximum of analgesia was done. Score was recorded every $5 \mathrm{~min}$ for 30 minutes preoperative.

- Motor block by the Bromage scale for motor assessment. Assessment of time of onset, time to reach maximum of motor block was done. Score was recorded every $5 \mathrm{~min}$ for 30 minutes preoperative.

\section{3- Hemodynamic assessment:}

- Monitoring of heart rate, blood pressure, oxygen saturation and respiratory rate was recorded intraoperatively every 30 minutes for 4 hours and every 6 hours postoperatively for 48 hours.

- Observation for the occurrence of hypotension, bradycardia and treatment accordingly.

\section{4- Incidence of complications as:}

(Epidural spread, vomiting, nausea and pruiritis) and LA toxicity symptoms and signs were reported.

\section{Statistical methodology:}

Results were presented as mean, SD, absolute numbers and percentage as appropriate. Error bars in the figures represent standard deviation. Statistical analysis of data was done using SPSS (statistical program for social science). Chi-square test was used to compare qualitative variables. Unpaired $t$-test was used to compare two independent groups as regard a quantitative variable. Fisher exact test was used instead of Chi-square test when one expected cell or more $<5$. The level of significance was set at a $p$-value less than 0.05 , while $p$-values $<0.01$ were considered highly significant.

\section{Results}

The study was performed over 40 patients. Five patients were excluded due to difficult catheter insertion or painful needle insertion without heavy sedation. Those patients were substituted with another 5 subjects to allow for completion of sample size. The patients were divided into two groups:

- Group CFIB $=20$ patients.

- Group CLPB=18 patients ( 2 patients failed to develop signs of sensory and motor block within 30 minutes of start of activation of the block with failure rate $=10 \%$ ).

\section{Characteristic data:}

The demographic data are presented in (Table 1). No statistically significant difference among both groups.

\section{Procedure technique:}

CFIB group had significantly shorter time for catheter insertion (CIT) $(p<0.001)$, earlier maximum motor block $(p<0.001)$ and earlier peak of sensory block ( $p=0.008)$, while CLPB group showed significantly rapid onset of motor and sensory block $(p<0.001, p<0.001)$ (Table 2), (Figs. 1,2,3).

Motor, sensory and sympathetic block assessment:

Intensity of motor block as scored according to Bromage scale revealed a statistically significant intense block in the CLPB compared to CFIB $(p=0.012,0.046,<0.001$ at $10,20,30$ minutes respectively). LPB started numbness at 5 minutes $(p<0.001)$, and complete sensory block at $20 \mathrm{~min}-$ utes $(p=0.017)$. CFIB started numbness at $10 \mathrm{~min}$ utes $(p=0.011)$ and complete sensory block at 30 minutes $(p<0.001)$. CLPB group had more frequent cases of sympathetic block with statistically significant difference from CFIB group with a $p$-value of $<0.001$ (Table 3 ).

\section{Intraoperative hemodynamic parameters:}

CLPB group had significantly slower heart rate and lower systolic and diastolic blood pressure as compared to CFIB $(p<0.001)$ (Figs. 4,5,6). Both groups were in average range (non-significant clinically) (Table 4).

Intraoperative respiratory parameters:Respiratory rate and oxygen saturation were assessed in both groups showed non-significant changes clinically and statistically (Table 5).

Table (1): Patients' characteristics in both study groups.

\begin{tabular}{lccccc}
\hline & Group=CFIB group & Group=CLPB group & $\mathrm{t} / \chi^{2}$ & df & $p$-value \\
\hline Age (years) & $60.8 \pm 7.1$ & $57.4 \pm 10.4$ & 1.169 & 29.521 & $0.252 \Phi$ \\
Gender (M/F) & $12 / 8$ & $13 / 5$ & & & $0.506 \S$ \\
BMI $\left(\mathrm{kg} / \mathrm{m}^{2}\right)$ & $23.8 \pm 3.2$ & $25.2 \pm 3.6$ & -1.290 & 36 & $0.205 \Phi$ \\
ASA-PS: & & & 0.132 & 1 & $0.717 ¥$ \\
ASA-PS I & $6(30.0 \%)$ & $8(44.4 \%)$ & & & \\
ASA-PS II & $12(60.0 \%)$ & $4(22.2 \%)$ & & \\
ASA-PS III & $2(10.0 \%)$ & $6(33.3 \%)$ & & \\
\hline
\end{tabular}


Table (2): Catheter insertion time and time to onset and to maximal sensory and motor block in both study groups.

\begin{tabular}{lcccccccc}
\hline \multirow{2}{*}{ Variable } & \multicolumn{2}{c}{$\begin{array}{c}\text { CFIB group } \\
(\mathrm{n}=20)\end{array}$} & \multicolumn{2}{c}{$\begin{array}{c}\text { CLPB group } \\
(\mathrm{n}=18)\end{array}$} & $\mathrm{U}$ & $\mathrm{Z}$ & $p$-valueII \\
\cline { 2 - 6 } & Median & IQR & Median & IQR & & & \\
\hline CIT (min) & 10 & $9-11$ & 13 & $12-13$ & 5.0 & -5.143 & $<0.001^{*}$ \\
Time to onset of motor block (min) & 11 & $9-13$ & 6 & $5-7$ & 0.0 & -5.305 & $<0.001^{*}$ \\
Time to maximal motor block (min) & 17 & $16-18$ & 22 & $20-24$ & 5.0 & -5.159 & $<0.001^{*}$ \\
Time to onset of sensory block (min) & 10 & $5-15$ & 5 & $5-5$ & 72.0 & -3.843 & $<0.001^{*}$ \\
Time to maximal sensory block (min) & 20 & $19-25$ & 30 & $20-30$ & 92.0 & -2.653 & $0.008^{*}$ \\
\hline
\end{tabular}

IQR, interquartile range. IIMann-Whitney test. * $p$-value $=0.05$ (significant) $<0.001$ (highly significant).

Table (3): Bromage, sensory, and sympathetic block scores in both study groups.

\begin{tabular}{|c|c|c|c|c|c|c|c|c|}
\hline \multirow{2}{*}{ Variable } & \multirow{2}{*}{ Time } & \multicolumn{2}{|c|}{$\begin{array}{l}\text { CFIB group } \\
(\mathrm{n}=20)\end{array}$} & \multicolumn{2}{|c|}{$\begin{array}{l}\text { CLPB group } \\
(n=18)\end{array}$} & \multirow{2}{*}{$\mathrm{U}$} & \multirow{2}{*}{$\mathrm{Z}$} & \multirow{2}{*}{$p$-value $\mathbb{I}$} \\
\hline & & Median & IQR & Median & IQR & & & \\
\hline \multirow[t]{4}{*}{ Bromage score } & $5 \mathrm{~min}$ & 2 & $2-2$ & 2 & $2-2$ & 180.0 & 0.000 & 1.000 \\
\hline & $10 \mathrm{~min}$ & 2 & $1-2$ & 2 & $2-2$ & 126.0 & -2.499 & $0.012 *$ \\
\hline & $20 \mathrm{~min}$ & 2 & $1-2$ & 2 & $2-2$ & 128.0 & -1.993 & $0.046^{*}$ \\
\hline & $30 \mathrm{~min}$ & 1 & $1-1$ & 2 & $1-2$ & 74.0 & -3.623 & $<0.001 *$ \\
\hline \multirow[t]{6}{*}{ Sensory block score } & $5 \mathrm{~min}$ & 0 & $0-1$ & 1 & $1-1$ & 72.0 & -3.920 & $<0.001 *$ \\
\hline & $10 \mathrm{~min}$ & 1 & $0-1$ & 1 & $1-1$ & 107.0 & -2.541 & $0.011 *$ \\
\hline & $15 \mathrm{~min}$ & 1 & $1-1$ & 1 & $1-2$ & 140.0 & -1.428 & 0.153 \\
\hline & $20 \mathrm{~min}$ & 1 & $1-2$ & 2 & $1-2$ & 108.0 & -2.383 & $0.017 *$ \\
\hline & $25 \mathrm{~min}$ & 1 & $1-2$ & 2 & $2-2$ & 64.0 & -4.005 & $<0.001 *$ \\
\hline & $30 \mathrm{~min}$ & 2 & $1-2$ & 2 & $2-2$ & 80.0 & -3.594 & $<0.001 *$ \\
\hline Sympathetic block score & $30 \mathrm{~min}$ & 0 & $0-0$ & 1 & $1-1$ & 0.0 & -5.959 & $<0.001 *$ \\
\hline
\end{tabular}

I[Mann-Whitney test. $* p$-value $=0.05$ (significant) $<0.001$ (highly significant).

Table (4): Intraoperative hemodynamic parameters in both study groups.

\begin{tabular}{|c|c|c|c|c|c|c|c|c|}
\hline \multirow[t]{2}{*}{ Variable } & \multirow[t]{2}{*}{ Time } & \multicolumn{2}{|c|}{$\begin{array}{l}\text { CFIB group } \\
(\mathrm{n}=20)\end{array}$} & \multicolumn{2}{|c|}{$\begin{array}{c}\text { CLPB group } \\
(\mathrm{n}=18)\end{array}$} & \multirow[t]{2}{*}{$t$} & \multirow[t]{2}{*}{ df } & \multirow[t]{2}{*}{$p$-value $\mathbb{I}$} \\
\hline & & Mean & $\mathrm{SD}$ & Mean & SD & & & \\
\hline Heart rate (bpm) & $\begin{array}{l}30 \mathrm{~min} \\
90 \mathrm{~min} \\
150 \mathrm{~min} \\
210 \mathrm{~min}\end{array}$ & $\begin{array}{l}80.1 \\
79.4 \\
80.9 \\
80.0\end{array}$ & $\begin{array}{l}5.3 \\
6.0 \\
6.5 \\
7.0\end{array}$ & $\begin{array}{l}64.4 \\
66.1 \\
64.1 \\
66.9\end{array}$ & $\begin{array}{l}4.0 \\
4.1 \\
4.0 \\
3.4\end{array}$ & $\begin{array}{l}10.169 \\
7.918 \\
9.489 \\
7.472\end{array}$ & $\begin{array}{l}36 \\
36 \\
36 \\
27.914\end{array}$ & $\begin{array}{l}<0.001 * \\
<0.001 * \\
<0.001 * \\
<0.001 *\end{array}$ \\
\hline $\mathrm{SBP}(\mathrm{mmHg})$ & $\begin{array}{l}30 \mathrm{~min} \\
90 \mathrm{~min} \\
150 \mathrm{~min} \\
210 \mathrm{~min}\end{array}$ & $\begin{array}{l}132.0 \\
130.0 \\
131.5 \\
133.5\end{array}$ & $\begin{array}{l}7.7 \\
3.2 \\
7.3 \\
6.1\end{array}$ & $\begin{array}{l}108.9 \\
108.6 \\
107.2 \\
104.2\end{array}$ & $\begin{array}{l}5.6 \\
7.4 \\
6.2 \\
7.1\end{array}$ & $\begin{array}{l}10.692 \\
11.274 \\
10.984 \\
13.683\end{array}$ & $\begin{array}{l}34.528 \\
22.726 \\
36 \\
36\end{array}$ & $\begin{array}{l}<0.001 * \\
<0.001 * \\
<0.001 * \\
<0.001 *\end{array}$ \\
\hline $\mathrm{DBP}(\mathrm{mmHg})$ & $\begin{array}{l}30 \mathrm{~min} \\
90 \mathrm{~min} \\
150 \mathrm{~min} \\
210 \mathrm{~min}\end{array}$ & $\begin{array}{l}79.5 \\
77.5 \\
77.0 \\
79.0\end{array}$ & $\begin{array}{l}4.3 \\
4.1 \\
5.7 \\
3.8\end{array}$ & $\begin{array}{l}60.6 \\
65.6 \\
64.4 \\
61.1\end{array}$ & $\begin{array}{l}5.1 \\
5.4 \\
4.8 \\
5.3\end{array}$ & $\begin{array}{l}12.452 \\
7.706 \\
7.280 \\
12.001\end{array}$ & $\begin{array}{l}36 \\
36 \\
36 \\
36\end{array}$ & $\begin{array}{l}<0.001 * \\
<0.001 * \\
<0.001 * \\
<0.001 *\end{array}$ \\
\hline
\end{tabular}

IIUnpaired $t$-test. $\quad{ }^{*} p$-value $=0.05$ (significant) $<0.001$ (highly significant).

Table (5): Intraoperative respiratory parameters in both study groups.

\begin{tabular}{|c|c|c|c|c|c|c|c|c|}
\hline \multirow{2}{*}{ Variable } & \multirow{2}{*}{ Time } & \multicolumn{2}{|c|}{$\begin{array}{c}\text { CFIB group } \\
(\mathrm{n}=20)\end{array}$} & \multicolumn{2}{|c|}{$\begin{array}{l}\text { CLPB group } \\
(\mathrm{n}=18)\end{array}$} & \multirow{2}{*}{$t$} & \multirow{2}{*}{ df } & \multirow{2}{*}{$p$-value $\Phi$} \\
\hline & & Mean & SD & Mean & SD & & & \\
\hline Respiratory rate (bpm) & $\begin{array}{l}30 \mathrm{~min} \\
90 \mathrm{~min} \\
150 \mathrm{~min} \\
210 \mathrm{~min}\end{array}$ & $\begin{array}{l}15.2 \\
14.9 \\
14.7 \\
14.9\end{array}$ & $\begin{array}{l}1.0 \\
0.7 \\
0.8 \\
0.6\end{array}$ & $\begin{array}{l}15.6 \\
15.9 \\
15.7 \\
16.0\end{array}$ & $\begin{array}{l}1.6 \\
1.6 \\
2.3 \\
2.0\end{array}$ & $\begin{array}{l}-0.823 \\
-2.495 \\
-1.710 \\
-2.289\end{array}$ & $\begin{array}{l}36 \\
36 \\
20.776 \\
19.404\end{array}$ & $\begin{array}{l}0.416 \\
0.017 \\
0.102 \\
0.033\end{array}$ \\
\hline $\mathrm{SpO}_{2}(\%)$ & $\begin{array}{l}30 \mathrm{~min} \\
90 \mathrm{~min} \\
150 \mathrm{~min} \\
210 \mathrm{~min}\end{array}$ & $\begin{array}{l}99.6 \\
99.4 \\
99.4 \\
99.5\end{array}$ & $\begin{array}{l}0.5 \\
0.5 \\
0.5 \\
0.5\end{array}$ & $\begin{array}{l}99.0 \\
98.9 \\
99.3 \\
99.1\end{array}$ & $\begin{array}{l}1.2 \\
1.0 \\
1.1 \\
1.4\end{array}$ & $\begin{array}{l}1.997 \\
1.804 \\
0.439 \\
1.332\end{array}$ & $\begin{array}{l}36 \\
36 \\
36 \\
36\end{array}$ & $\begin{array}{l}0.053 \\
0.080 \\
0.663 \\
0.191\end{array}$ \\
\hline
\end{tabular}

qIUnpaired $t$-test. $\quad * p$-value $=0.05$ (significant) $<0.001$ (highly significant). 


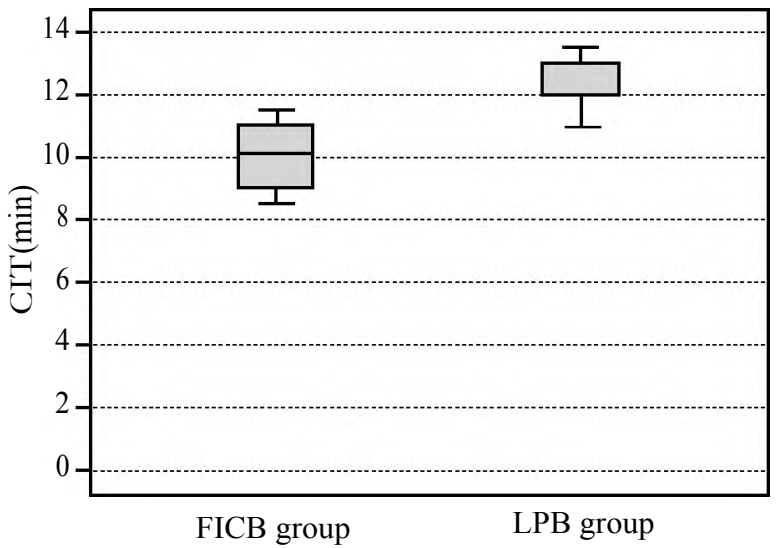

Fig. (1): Box plot showing the catheter insertion time in both study groups.
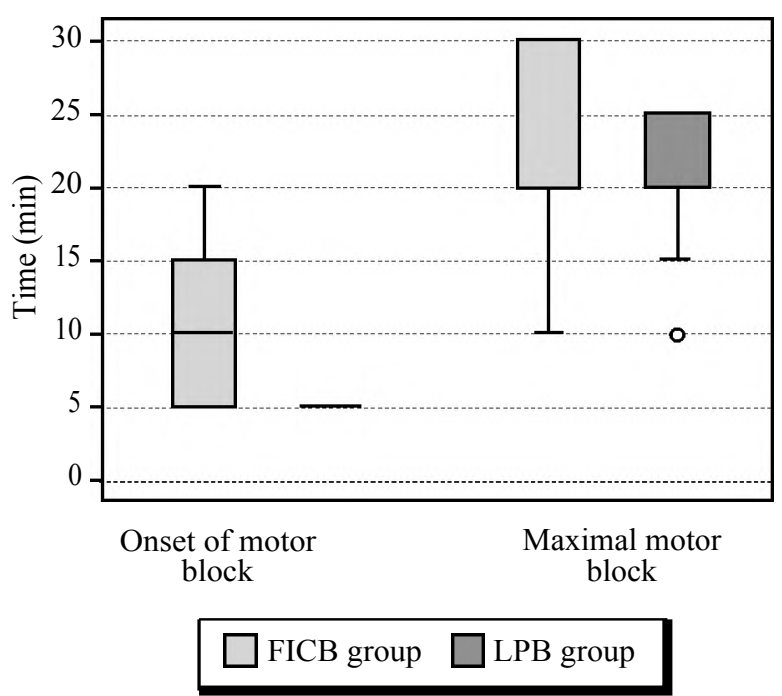

Fig. (3): Box plot showing the time to onset and to maximal sensory block in both study groups.
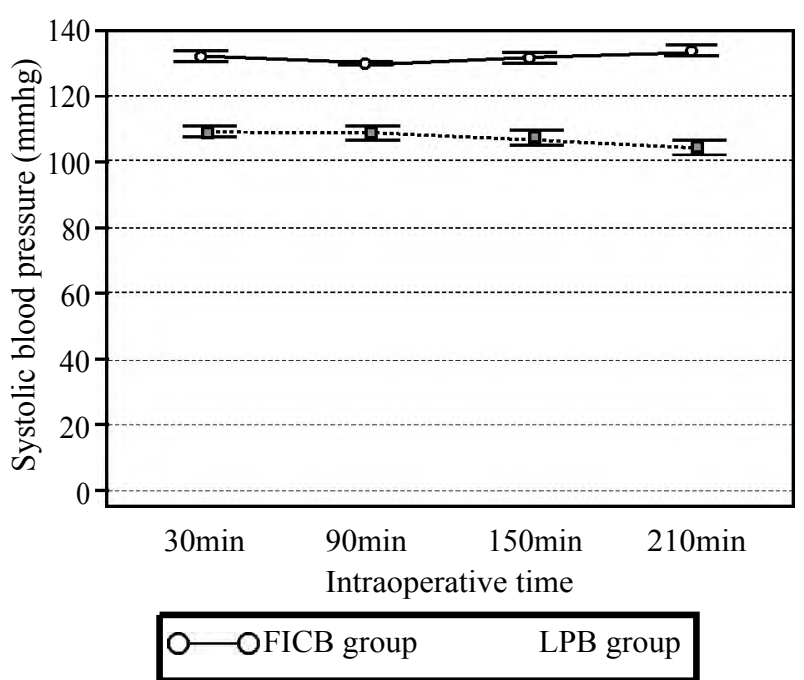

Fig. (5): Mean intraoperative systolic blood pressure in both study groups. Error bars represent the standard error of the mean (SEM).

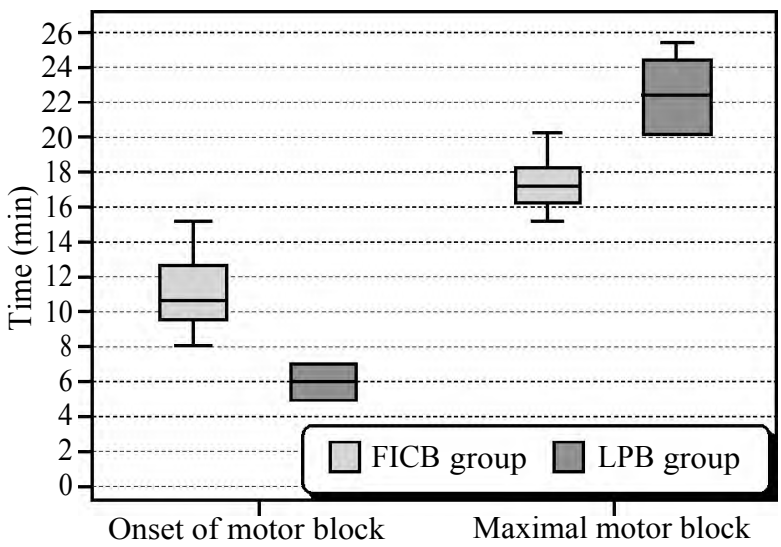

Fig. (2): Box plot showing the time to onset and to maximal motor block in both study groups.
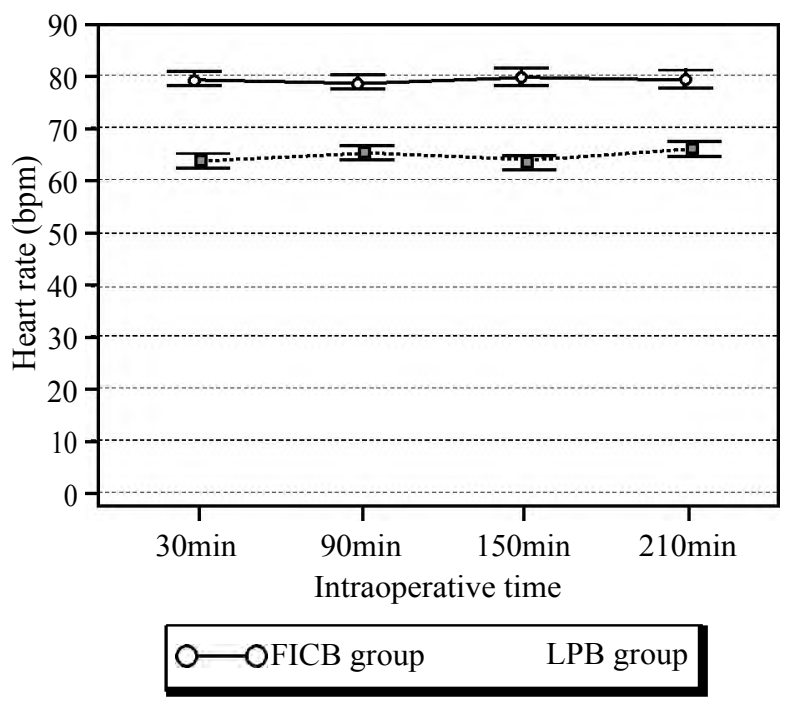

Fig. (4): Mean intraoperative heart rate in both study groups. Error bars represent the standard error of the mean (SEM).
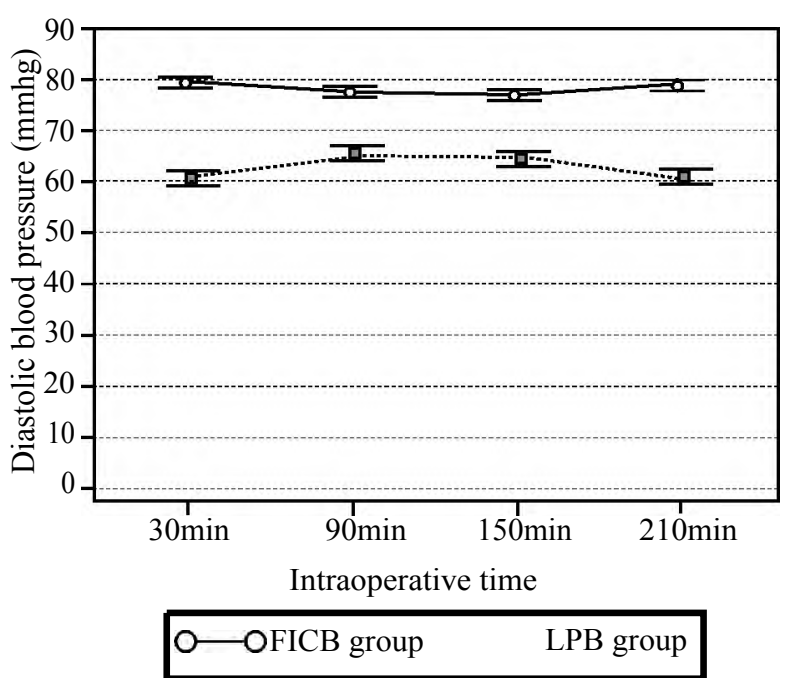

Fig. (6): Mean intraoperative diastolic blood pressure in both study groups. Error bars represent the standard error of the mean (SEM). 


\section{Discussion}

Hip fractures are painful and pain left untreated can result in complications that may delay operative intervention and complicate hospital stay [5]. Pain management in many hospitals is based upon the use of systemic analgesia. Many guidelines suggest considering the use of neural blockade by trained personnel to limit opioid dosage and its complications [6]

CFIB group had significantly shorter time for catheter insertion (10min) than CLPB group $(13 \mathrm{~min})(p<0.001)$. This may be explained by the simplicity of the procedure. In their study, Möller et al, said that when compared to continuous femoral nerve block (CFNB), CFIB was shorter in catheter insertion time (CIT) [7]. In another study comparing CFNB and CLPB, Sayed and Yousef, concluded that CFNB showed significantly shorter CIT [8].

Regarding preoperative sensory nerve block, in the present study, it occurred significantly earlier and more intense in CLPB than CFIB $(5,10 \mathrm{~min}$ respectively) $(p<0.001)$. Peak of sensory block occurred more rapidly in CFIB than CLPB (20, $30 \mathrm{~min}$ respectively) $(p=0.008)$. Preoperative motor block started to occur in CLPB group earlier than CFIB $(6,11$ min each) $(p<0.001)$. Maximal motor block occurred faster in CFIB than CLPB group $(17,22 \mathrm{~min}$ each) $(p<0.001)$. Dulaney-Cripe et al., said that, the fact that CLPB is a high block that is administered near the roots and affects femoral, lateral cutaneous, obturator, ilioinguinal, iliohypogastric and genitofemoral nerves may explain the early onset of sensory and motor blocks [9] The fascia iliaca compartment is a triangular potential space, which may explain the earlier reaching to maximum of anesthesia [2]. While fascia iliaca block (FIB) (anterior approach) is effective in blocking lateral femoral cutaneous and femoral nerves, it shows less efficacy in blocking obturator nerve [10]. On the other hand the lumbar plexus block (LPB) (posterior approach) is effective in blocking the obturator nerve (the articular branches innervate the anteromedial capsule of hip joint) together with lateral femoral cutaneous and femoral nerves [11]. De Leeuw et al., found that, In patients undergoing hip arthroplasty, the analgesic potency of single injection (bolus dose) LPB compared with patient controlled analgesia, femoral nerve block and intravenous morphine was found significantly higher $(p=0.001)$ [11]. The large volume of bolus dose in single injection LPB contributes to the potent initial motor and sensory block [12].
In the current study, the preoperative sympathetic block occurred more frequently in LPB group $(p<0.001)$. De Visme et al., described decrease in mean arterial blood pressure after CLPB [1]. LPB results in unilateral sympathectomy that may lead to hemodynamic instability. Moreover, in cases complicated with epidural diffusion, bilateral sympathectomy is possible [10]

Regarding hemodynamics, in the present study, intraoperative hemodynamics showed significant lowering of blood pressure and heart rate in the LPB compared to FICB $(p<0.001)$. This could be explained by the maximum sympathectomy that occurs secondary to the additive effect of both bolus dose of LPB and the spinal anaesthesia. Monitoring of vital signs 48 hours postoperative also showed significant lowering of both heart rate and blood pressure in CLPB ( $p=0.024, p<0.001)$, which may be attributed to the sympathectomy effect of the infusing dose of CLPB.

\section{Conclusions:}

Continuous infusion fascia iliaca block gives better quality analgesia. It is an easy procedure that could be done in the emergency room. It is faster, safer and more applicable technique than continuous lumbar plexus block.

\section{References}

1- de VISME V., PICART F., LE JOUAN R., LEGRAND A., SAVRY C. and MORIN V.: Combined lumbar and sacral plexus block compared with plain bupivacaine spinal anesthesia for hip fractures in the elderly. Regional anesthesia and pain medicine. Apr., 30, 25 (2): 158-62, 2000.

2- RANGE C. and EGELER C.: Fascia iliaca compartment block: landmark and ultrasound approach. Anaesthetic Tutorial of the Week, 193: 1-4, 2010.

3- DESCHNER B.O., ROBARDS C.H., XU D.A., SOMASUNDARAM L. and HADZIC A.: A comprehensive review of lower extremity peripheral nerve blocks. The Journal of the New York School of Regional Anesthesia, 12: 11-22, 2009.

4- KOSCIELNIAK-NIELSEN Z.J.: Ultrasound-guided peripheral nerve blocks: What are the benefits?. Acta Anaesthesiologica Scandinavica, Jul., 1, 52 (6): 727-37, 2008.

5- VISCUSI E.R. and PAPPAGALLO M.: A review of opioids for in-hospital pain management. Hospital Practice. Feb., 1, 40 (1): 149-59, 2012.

6- HANNA L., GULATI A. and GRAHAM A.: The Role of Fascia Iliaca Blocks in Hip Fractures: A Prospective CaseControl Study and Feasibility Assessment of a JuniorDoctor-Delivered Service. ISRN orthopedics. Mar., 4, 2014.

7- MÖLLER T., BENTHAUS S., HUBER M., BENTRUP I., SCHOFER M., EBERHART L., WULF H. and MORIN 
A.: A Randomized and Observer Blinded Comparison of Continuous Femoral Block and Fascia Iliaca Compartment Block in Hip Replacement Surgery. J. Anesthe. Clinic. Res., 4 (277): 3, 2011.

8- SAYED A.M. and YOUSEF K.: Continuous femoral nerve against psoas compartment block for analgesia in total knee arthroplasty. Ain-Shams Journal of Anaesthesiology. Apr., 1, 8 (2): 200, 2015.

9- DULANEY-CRIPE E., HADAWAY S., BAUMAN R., TRAME C., SMITH C., SILLAMAN B. and LAUGHLIN R.: A continuous infusion fascia iliaca compartment block in hip fracture patients: A pilot study. Journal of Clinical Medicine Research. Feb., 4 (1): 45, 2012.
10- CAPDEVILA X., COIMBRA C. and CHOQUET O.: Approaches to the lumbar plexus: success, risks, and outcome. Regional anesthesia and pain medicine. Apr., 30, 30 (2): 150-62, 2005.

11-De LEEUW M.A., ZUURMOND W.W. and PEREZ R.S.: The psoas compartment block for hip surgery: The past, present, and future. Anesthesiology Research and Practice. May., 22, 2011.

12-ABDELMAWGOUD A. and RASHWAN S.: The analgesic efficacy of continuous fascia iliaca block vs. continuous psoas compartment block after hip surgery: A comparative study. Egyptian Journal of Anaesthesia. Jul., 31, 28 (3): 183-7, 2012

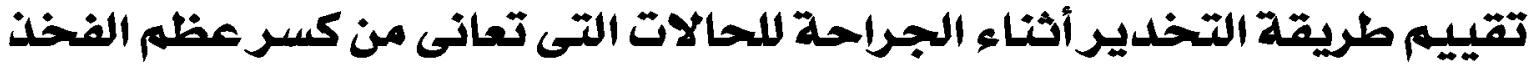

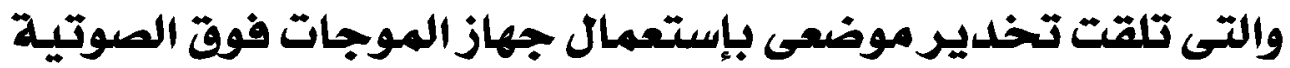

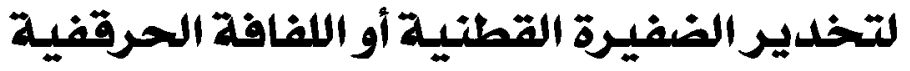

الخخلفة: فى المرضى كبار السن والمخاطر العالية، فمن المنطقى أن يفضل التخدير الموضعى بدلاً من التخدير العام. CFIB هي طريقة

سـهلة ومتوفرة للتسكين ثبه المنطقى في المرضيى الذين يعانون من حالات مؤلمة تؤثر على الفخذ، مفصل الورك و/أو عظم الفخذ . CLPB

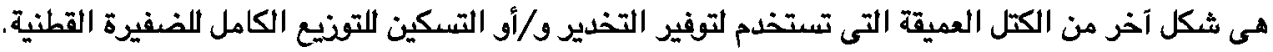
الهدف من الدراسة": التقييم أثثاء العملية من CFIB مقابل CLPB.

المواد والطرق: تم عشوائية . ع مريضاً يعانون من كسر عظمة الفخذ فى أحل من CFIB و CLPB.

النتائج: كان CFIB أعلى بكثير من CLPB فيما يتعلق بالوقت الأقصر لإدخال القسطرة (CIT) (C)>0.001)، وكتلة المحرك القصوىى السابقة (001<0.001) والذروة السابقة للكتلة الصسية (0.008=0.

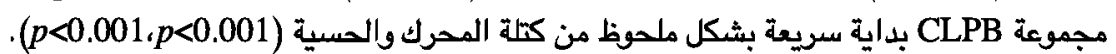

الخلاصهة: CFIB يعطى تسكين أفضل جودة إنه إجراء سهل يمكن القيام به فى غرفة الطوارء إنها تقنية أسرع وأكثر أماناً وأكثر قابلية

للتطبيق هن CLPB. 